\title{
Calibration of Dynamic Tool-Workpiece Interface Temperature Measurement during Friction Stir Welding
}

\author{
Joshua Schmale, Axel Fehrenbacher, Amber Shrivastava, Frank E. Pfefferkorn* \\ Department of Mechanical Engineering, University of Wisconsin-Madison, USA \\ * corresponding author \\ Frank E. Pfefferkorn, Ph.D. \\ 1513 University Ave. \\ Madison, WI 53706 \\ (608) 263-2668 \\ pfefferk@engr.wisc.edu \\ keywords: thermocouple, calibration, transient response, friction stir welding
}

\begin{abstract}
The objective of this work is to accurately measure the transient temperatures at the toolworkpiece interface during friction stir welding (FSW) using thermocouples that are embedded in the tool. Temperature sensors embedded in the friction stir (FS) tool provide a non-consumable localized temperature measurement capability that is crucial for process research, development, and control. A modification of the ASTM E-1461 standard for measuring thermal diffusivity with pulses of heat flux is proposed for calibrating the transient response of temperature sensors located near the surface of the FS tool. These tests enable the calculation of each sensor's time constant, which are used in one-dimensional analytical models of the dynamic response to calculate the true interface temperature. Time constants between 21 and $43 \mathrm{~ms}$ are measured for 0.25 -mm-diameter, sheathed thermocouples located at the FS tool surface.
\end{abstract}




\section{Nomenclature}

$c$

$C_{0}$

$d_{p}$

$d_{s}$

$E^{\prime \prime}$

$k$

$L$

$P$

$t$

$T_{0}$

$T$

$T_{\text {ini }}$

$T_{\max }$

$x$

$\underline{\text { Greek Symbols }}$

$\begin{array}{ll}\alpha & \text { Thermal diffusivity, } \mathrm{m}^{2} / \mathrm{s} \\ \Delta T & \text { Temperature oscillation amplitude, } \mathrm{K} \\ \rho & \text { Density, } \mathrm{kg} / \mathrm{m}^{3} \\ \sigma_{\tau} & \text { Standard deviation of measured time constant } \\ \tau & \text { Time constant governing dynamic response, } \mathrm{s} \\ \omega & \text { Angular frequency of spindle, } \mathrm{rad} / \mathrm{s}\end{array}$

Specific heat, $\mathrm{J} / \mathrm{kg}-\mathrm{K}$

Temperature fit coefficient of magnitude, -

FS tool probe diameter, $\mathrm{m}$

FS tool shoulder diameter, $\mathrm{m}$

Thermal conductivity, $\mathrm{W} / \mathrm{m}-\mathrm{K}$

Distance to temperature measurement location, $\mathrm{m}$

Power, W

Time, $\mathrm{s}$

Initial thermocouple temperature, $\mathrm{K}$

Temperature, $\mathrm{K}$

Initial material temperature, $\mathrm{K}$

Maximum temperature rise, $\mathrm{K}$

Amount of instantaneous energy released per unit area, $\mathrm{J} / \mathrm{m}^{2}$

Distance from surface of material; distance from tool shoulder, $\mathrm{m}$ 
does not melt during welding, i.e., temperatures stay below the solidus. Creating a metallurgical joint in this temperature range results in desirable properties. Furthermore, the process can be more energy efficient and environmentally friendly than contemporary fusion welding processes [2], and has the potential for broad application [3].

The basic FSW apparatus consists of a non-consumable rotating friction stir (FS) tool, the workpieces, a fixture capable of rigidly holding the workpieces, and a machine for generating the relative motion between the FS tool and workpieces as well as the required spindle torque, plunge and traverse forces (Figure 1). The FS tool consists of a nominally flat shoulder with a protruding probe, which is usually frustum shaped and includes features such as flats and threads. During the weld, the rotating tool is moved into the workpiece to a desired plunge depth. After the FS tool reaches its plunge depth the traverse portion of the weld begins. During this phase, the tool continues to rotate as it travels along the weld seam. The rotation of the FS tool moves and mixes the workpiece material resulting in a solid-state joint being formed behind the tool. The weld zone material experiences severe plastic deformation (high strains and strain rates), hence the process causes significant microstructural evolution for typical weld parameters $[3,4]$.

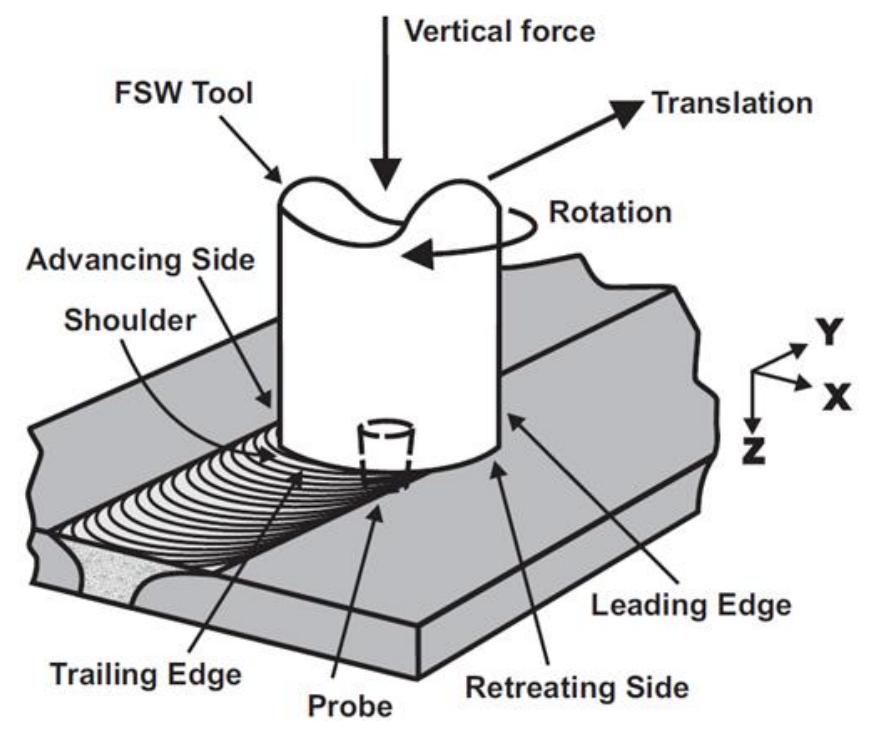

Figure 1: Schematic of friction stir butt weld [3]. 


\subsection{Importance of Temperature in Friction Stir Welding}

As is common to other types of welding, knowledge of the heat input and characterization of the weld zone temperature distribution provide important insights into the process. Figure 2 shows the friction stir weld zone in greater detail.

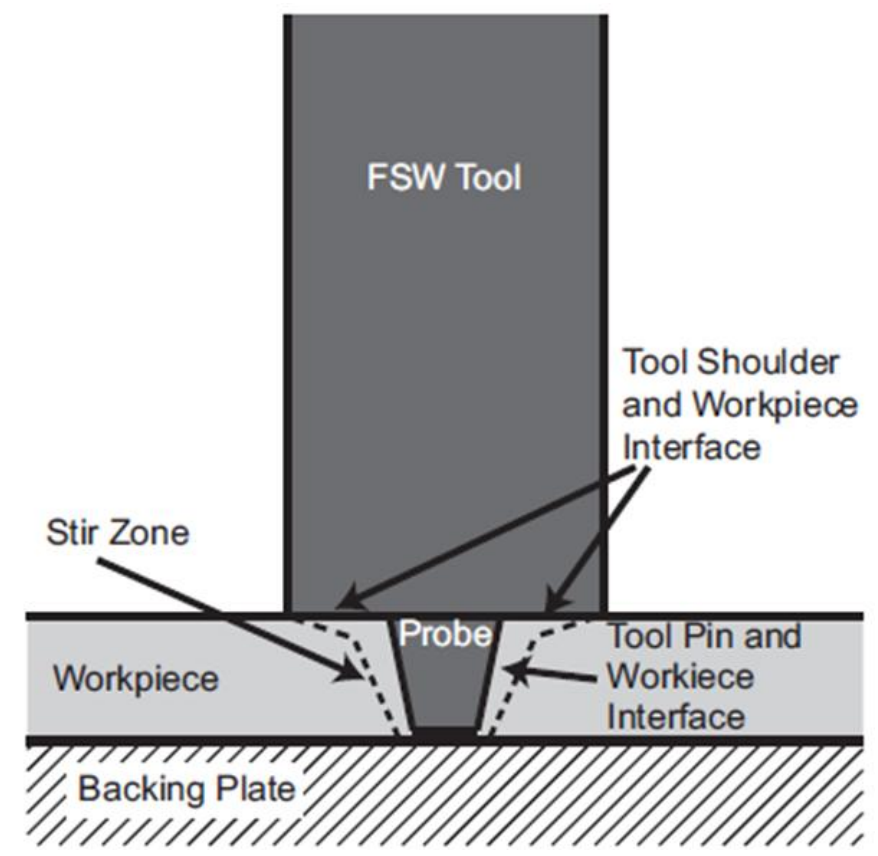

Figure 2: Areas of interest related to temperature in friction stir welding (FSW).

It is the stir zone temperature distribution along with the deformation history that determines the microstructural changes that the material undergoes. The microstructure is related to the weld strength, ductility, and toughness. Therefore, the mechanical weld properties are related to the temperatures in the weld-zone. For example, Peel et al. [5] report that resultant weld properties were dominated by the thermal input to the weld. They even go so far as to state that thermal effects are more important than the mechanical deformation caused by the FS tool. Gratecap et al. [6] found a qualitative effect of weld temperature on weld quality. Edwards et al. [8] demonstrate that weld zone microstructure (grain size) is qualitatively related to the weld-zone temperature. Recently completed measurement of weld-zone temperature by Fehrenbacher et al. [9] showed that weld failure mode and weld efficiency can be related to a minimum temperature limit. Fast and accurate measurement of weld zone temperature is of great 
interest for process understanding and control in friction stir welding. Fehrenbacher et al. [10] used the same thermocouple-based temperature sensors described in this paper to measure the FS tool-workpiece interface temperature and maintain a desired temperature in the presence of disturbances. Shrivastava et al. [11] describe how changes in measured temperature can be related to the creation of a discontinuity (e.g., void) in the weld, which require the accurate detection of faster temperature transients as the void size decreases and frequency of discontinuity occurrence increases.

\subsection{Temperature Measurement In Friction Stir Welding}

As is also common to other welding processes, measurement of the weld zone temperature provides an instrumentation challenge. An ideal temperature measurement system would provide information with fine spatial and temporal resolution throughout the weld zone. In general, four categories of temperature measurement during FSW have been used: neutron diffraction, infrared thermometry, embedded temperature sensors (RTD, thermocouple, etc.) in the workpiece, and embedded temperature sensors in the tool.

Woo et al. [12] measured temperature during FSW by using neutron diffraction. This method measures the lattice spacing within a material. The lattice spacing of atoms within aluminum is a function of only the stress state in the material and the temperature. As long as these two effects can be decoupled, temperature in the weld zone can be calculated. Uncertainty in the temperature arises from assumptions that have to be made about the stress distribution in the weld zone. The scarcity of neutron sources prevents widespread use of this method.

Another method of temperature measurement in FSW is infrared thermometry: using a pyrometer or infrared camera. The measurement is non-contact making this a viable candidate for examining welds during industrial scale production $[13,14]$. Fine spatial resolution of surface temperature can be achieved for the FS tool [15] and workpiece. Infrared thermometry relies on measurement of the radiation emitted by the surface of interest. The greatest challenge in applying infrared thermometry to friction stir welding is reflected radiation from adjacent surfaces that are at similar temperatures, i.e., the FS tool and weld 
surface (Figure 1). This problem is compounded by the relatively low emissivity (i.e., high reflectivity) of welded aluminum surfaces. Fehrenbacher et al. [29] were unable to make repeatable surface temperature measurements during FSW of aluminum with a two-color (i.e., two wavelength) pyrometer. The challenges associated with making accurate, and repeatable, temperature measurements with infrared thermometry during FSW should not be under-estimated.

Conventional temperature sensors (RTDs, thermocouples) can also be embedded in the workpiece. This was one of the first published techniques used to measure FSW temperatures. Typically, thermocouples embedded in the workpiece or backing plate have been placed some distance away from the weld zone so that they are not damaged during the welding process [17], [18]. Thermocouples can also be embedded in the workpiece, in the path of the tool [8]. This allows temperature to be measured up to the edge of the weld zone, at which point shear forces will destroy the sensor. Therefore, temperatures in the heat affected zone (HAZ) and most of the thermo-mechanically affected zone (TMAZ) can be measured. However, temperatures cannot be measured in the weld nugget where severe plastic deformation occurs. This technique requires a significant instrumentation effort for each weld, unless multiple welds are performed in the same location (i.e., on top of one another).

Temperature sensors can be embedded in the FS tool. This reduces the effort required for instrumentation for each weld because the tool and embedded sensors are non-consumable. If the temperature sensors have a fast enough response time and are placed close enough to the surface, then accurate tool-workpiece interface temperatures can be determined. Drilling through-holes in the FS tool and placing temperature sensors directly at the tool surface (i.e., tool-workpiece interface), where they are in direct contact with the weld material will provide the fastest response time. Within the FSW community, embedding thermocouples in through-holes in the FS tool was first undertaken by Gerlich et al. [19,20]. A stationary FS tool was instrumented for welding a rotating workpiece, reducing instrumentation difficulty but limiting the apparatus to spot welding applications. Through-hole temperature sensors were placed at the surface of the probe and the surface of the shoulder, with the 
thermocouples in direct contact with the weld material. The thermocouples used in Gerlich et al.'s research (0.25-mm-diameter) allow for response times of less than 100 milliseconds. Others have applied the through-hole method to measure tool-workpiece interface temperatures during FSW (butt welding) of aluminum [21] and use the signals in a closed-loop feedback algorithm to control weld temperature [29] as well as for detecting voids as they form in the weld [11] (see Section 1.3).

It is not always possible to drill holes through a FS tool because the stress concentration it creates will cause premature tool failure. Therefore, most of the research on measuring temperatures in the tool have the sensors embedded inside metal FS tools or on the back side of ceramic tools. Sterling et al. [22] measured the temperature on the back side of a polycrystalline cubic boron nitride (PCBN) tool while welding steel. Because of the distance from the tool-workpiece interface to the sensors and the thermal diffusivity of PCBN the response time is on the order of seconds. Cederqvist et al. [23] used toolembedded temperature sensors to control FSW of copper. The sensors were placed above the tool shoulder inside a tungsten alloy FS tool and had a response time of 15-20 seconds to changes in weld power [25-26]. Moving these sensors closer to the tool shoulder and locating one inside the tool probe reduced response times to $1-5$ seconds.

Tool embedded temperature sensors have also been combined with wireless data transmission. The experimental apparatus used by Blignault et al. [27] included a 0.5-mm-diameter K-type thermocouple embedded in the probe of an FS tool. This configuration had an estimated response time of 150 milliseconds [28]. Ideally, the sensor response time needs to be shorter than this. If temperature data from a sensor on the tool is to be spatially resolved (for a nominal spindle speed of $1000 \mathrm{RPM}$ ), the response time needs to be faster than 60 milliseconds. More importantly, the response time must be accurately determined and any delays accounted for. Otherwise, it is not possible to accurately calculate the transient tool-workpiece interface temperature from the measured values.

\subsection{Temperature Measurement Apparatus}


Work by A. Fehrenbacher has shown that it is desirable to have fast control of the FSW process [29]. To achieve this, a tool embedded temperature measurement apparatus was constructed using wiretype thermocouples mounted inside a stainless steel sheath (Omega model TJ36-CAXL-010U). A standard FS tool was fabricated from $\mathrm{H} 13$ tool steel with through holes extending from the sides of the tool above the shoulder, to points on the shoulder and probe (Figure 3). These holes were created by electrical discharge machining (EDM).

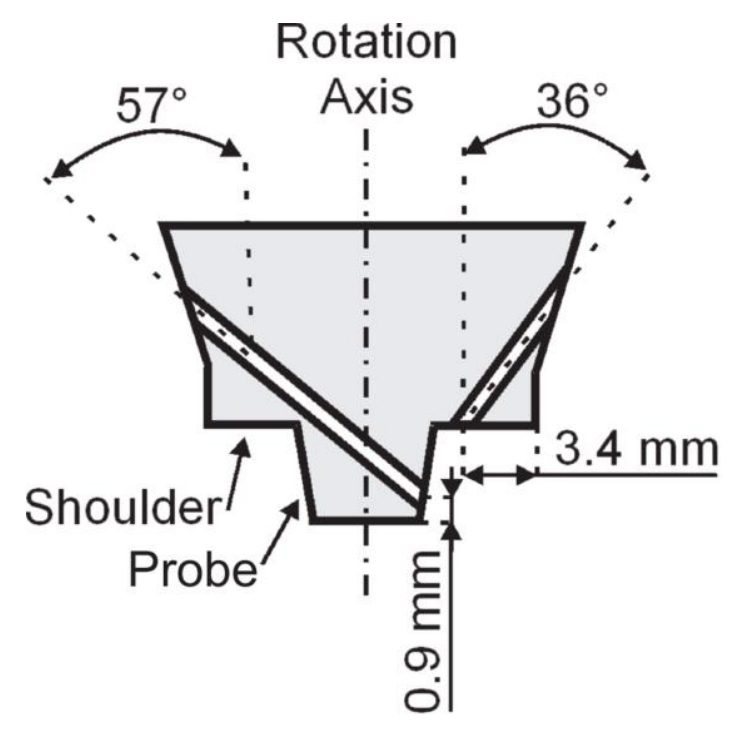

Figure 3: Cross-section of FS tool (H13 tool steel; 15-mm-diameter shoulder; 5.1-mm-long probe with 7-mm-diameter base and 5-mm-diameter tip) showing locations of through holes.

The sensors were secured in place with thermocouple cement (OmegaBond 600). Figure 4 shows the location of the thermocouples on the FSW tool probe and shoulder.

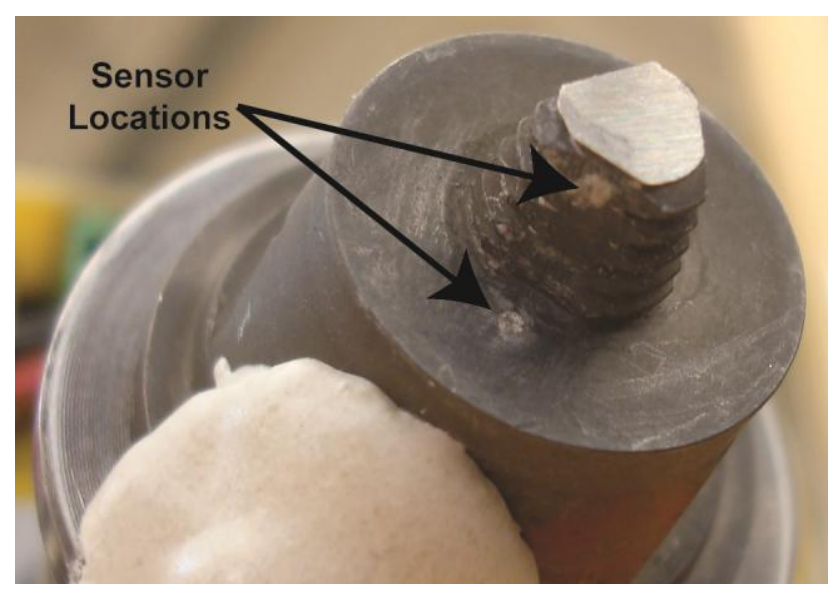

Figure 4: Completed FS tool with thermocouple locations noted. 
The thermocouple temperature data is transmitted from the rotating tool by a wireless data acquisition system so that the data can be gathered in real time and used for closed loop control of temperature [29]. Using this temperature measurement system, many aspects of the FSW process have been investigated and closed loop control of the weld zone temperature has been implemented [29]. The instrumented tool has also been used for development of empirical models for the response of the weld temperature (i.e., the weld process) to changes in weld parameters.

The instrumented tool has allowed a temperature profile for a single butt welded joint to be recorded (Figure 5). In the first region (I), the temperature is constant prior to the FS tool making contact with the workpiece. In the second region (II), the rotating tool is slowly plunging into the workpiece as temperatures increase. The probe is engaged before the shoulder makes contact, hence the probe temperature is higher. Once the shoulder makes contact with the workpiece at the end of region (II) the shoulder temperature exceeds the probe temperature. This is followed by a 3 seconds dwell. In the third region (III), the tool is traversed along the joint, welding the two workpieces together. The temperature behavior at this point is in a quasi steady state - it oscillates about a relatively constant value. In the final region (IV), the tool is retracted from the workpiece and the temperatures decrease.

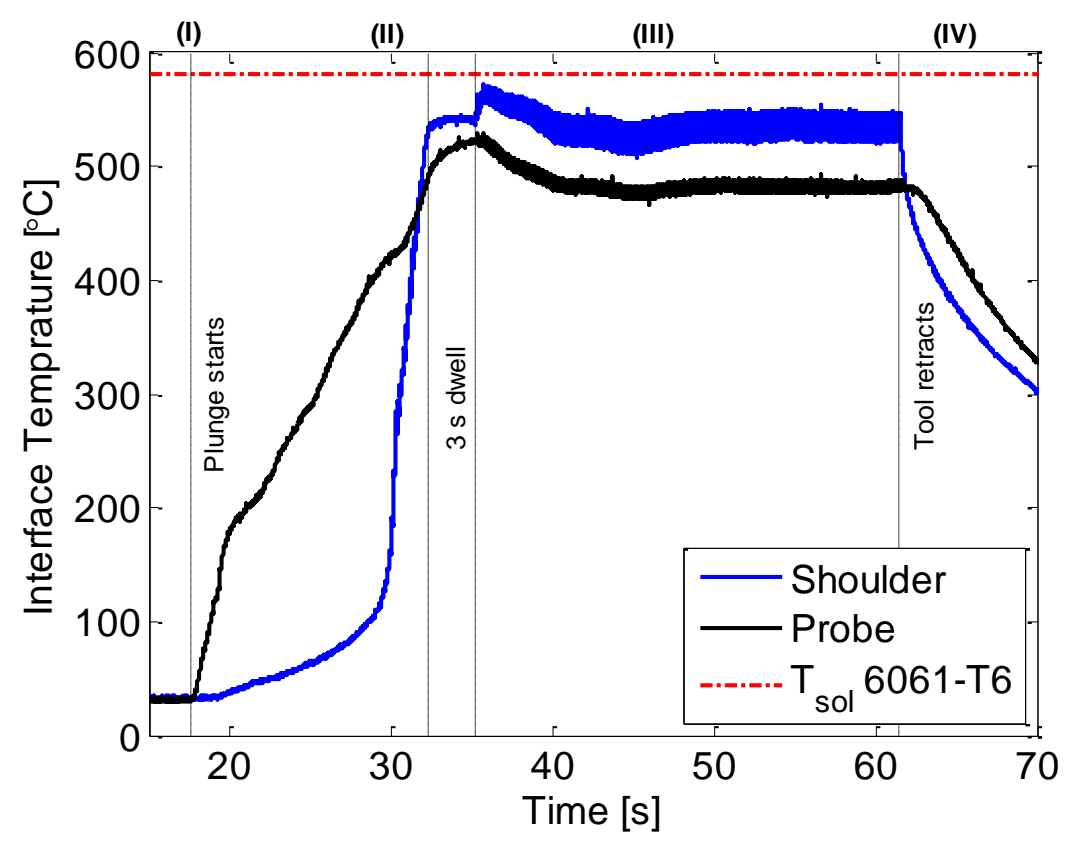


Figure 5: FSW temperatures at tool-workpiece interface (butt weld, 6061-T6 aluminum, 1100 rpm spindle speed, 300 $\mathrm{mm} / \mathrm{min}$ travel speed).

If one zooms into the temperatures in the quasi steady state region (III), a remarkable effect can be seen (Figure ). As the tool rotates, the temperature sensor sweeps out a circular path on the surface (shoulder) or inside (probe) the workpiece. Along this path, the temperature varies in a roughly sinusoidal manner. These temperature variations are a result of the process not being symmetric and will provide important information about the process. However, it is important to remember that the temperatures observed by the thermocouples (Figures 5 and 6) are not identical to the tool-workpiece interface temperature. The sensor response dynamics result in attenuation and phase shifts, even for sensors positioned very close to the tool-workpiece interface. In order to understand the true weld-zone temperature distribution, the transient response dynamics of the sensor must be determined.

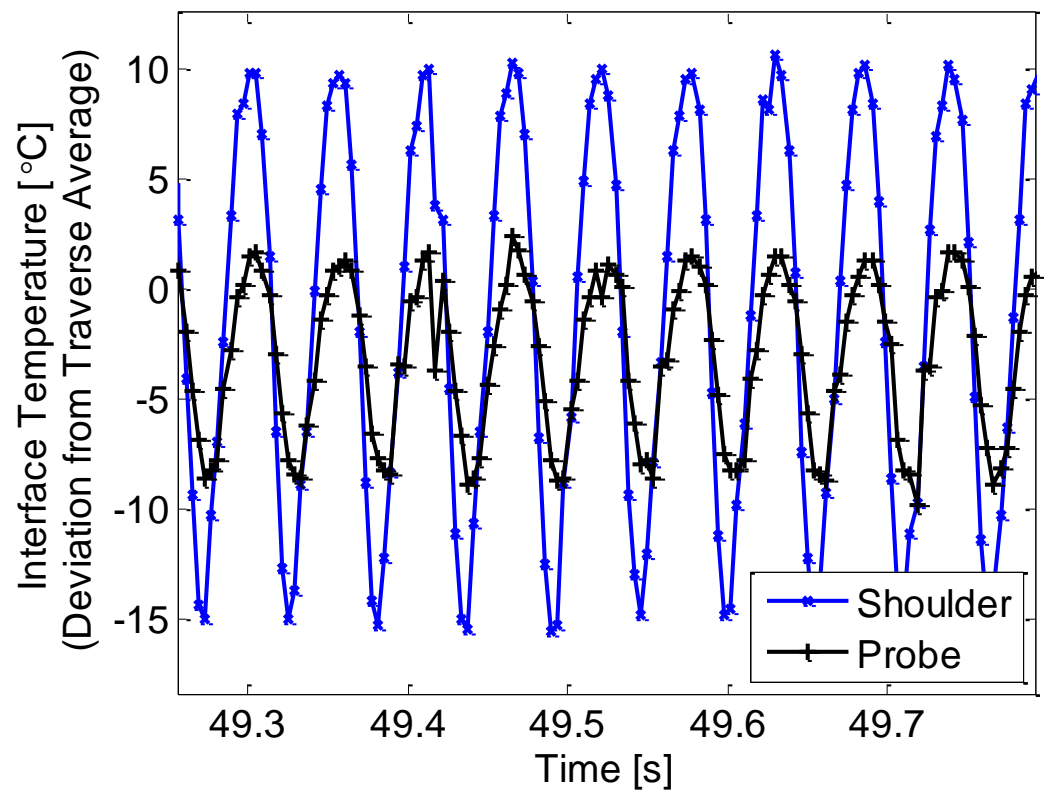

Figure 6: Deviation from average temperature at probe and shoulder for several tool rotations (welding conditions in Figure 5)

\section{Models of Thermocouple Response}


In order to describe its transient response, a model was sought to describe the heat transfer process between the tool surface and the thermocouple located in the sensor. This model was initially developed for the sensor in the FS tool shoulder. It is assumed that the sensor is in direct contact with the workpiece. On the length scale of the thermocouple, the size of the FS tool shoulder is much larger than the distance from the tip of the sheath to the measurement junction within the thermocouple (Figure ). The first model is an analytical, one-dimensional, semi-infinite model of the sensor in the tool (Section 2.1). This analytical model required the assumption of homogeneous material properties (Figure 7c). In reality, there exist several layers of different materials through which thermal energy must pass (Figure 7b). The FS tool is made of H13 tool steel. The K-type, ungrounded, sheathed thermocouple (Omega TJ36-CAXL010U) has a thermocouple junction that is surrounded by magnesium oxide $(\mathrm{MgO})$ and a sheath made of a proprietary metal alloy (OmegaClad XL alloy). The thermocouple assembly is mounted in the through hole with thermocouple cement (OmegaBond 600). Other assumptions for the semi-infinite body model that are not entirely satisfied are: isotropic material because the through hole and thermocouple probe are made of various materials and are not perpendicular to the tool shoulder surface (Figures 3 and 7a), and that the domain is initially at a uniform temperature. Therefore a numerical, two-dimensional, axisymmetric heat transfer model was developed (Section 2.2) to better understand the effect of the geometry and various materials present in this system. 


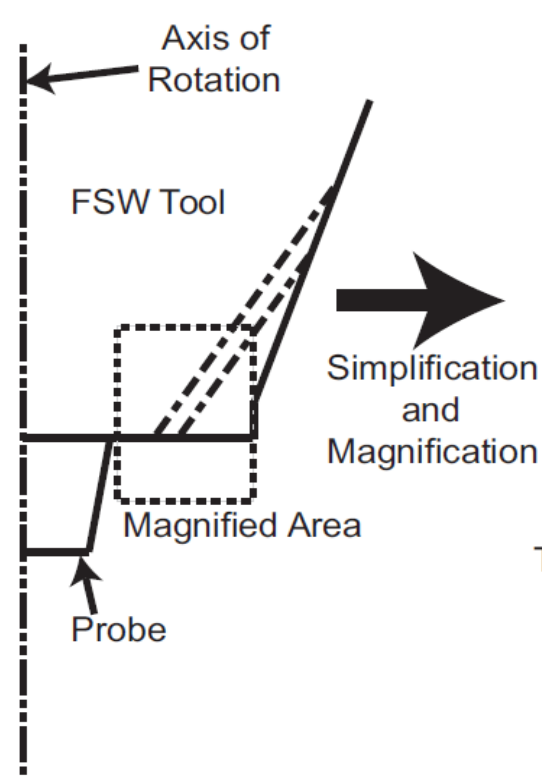

(a)

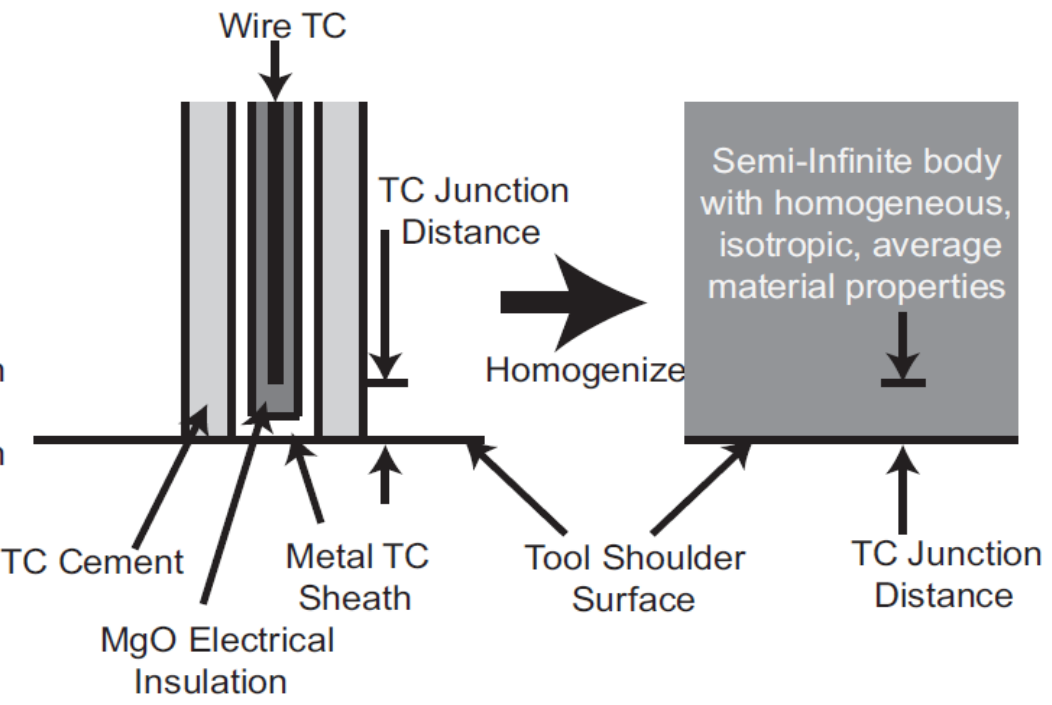

(b) (c)

Figure 7: Schematic of problem domain and simplifying assumptions: (a) cross-section of FS tool with through hole for shoulder temperature measurement, (b) magnified view of mounted thermocouple, and (c) sensor location in semi-infinite body.

\subsection{The 1-D Semi-Infinite Model}

If one assumes a sinusoidally varying temperature at the surface of this semi-infinite body (similar to the observed data in Figure 6), the temperature at a given location and time within the body is given by [30]

$$
T(L, t)-T_{i n i}=\Delta T \exp \left(-L \sqrt{\frac{\omega}{2 \alpha}}\right) \sin \left(\omega t-L \sqrt{\frac{\omega}{2 \alpha}}\right)
$$

where, $T(L, t)$ is the temperature for a given location $L$ measured from the surface, $\mathrm{T}_{\text {ini }}$ is the initial material temperature (the average weld temperature in the case of FSW), $\Delta T$ is the amplitude of the temperature oscillations, $\alpha$ is the assumed average thermal diffusivity, and $\omega$ is the angular velocity of the input (for FSW, this is the tool rotation speed, in radians per second). As discussed earlier, it is necessary to use average material property information in determining a value for $\alpha$. A nominal distance to the measurement junction must also be assumed. As $L$ is increased, the measured temperature is phase shifted and attenuated with respect to the surface temperature signal. The attenuation factor is given by 


$$
\exp \left(-L \sqrt{\frac{\omega}{2 \alpha}}\right)
$$

For example, if Eq. (2) had a magnitude of 0.6 , and a $\Delta T$ of $10^{\circ} \mathrm{C}$ existed at the surface, the measured amplitude at the measurement junction would be $6^{\circ} \mathrm{C}$. The amount of delay, in radians of tool rotation, is given by

$$
-L \sqrt{\frac{\omega}{2 \alpha}}
$$

Equations (2) and (3) are the product of two groups: $\sqrt{\omega}$ is a weld parameter that can be set by the operator; the second group is

$$
\frac{L}{\sqrt{\alpha}}
$$

Equation (4) is a function of the average thermal diffusivity and the distance from the tool surface (i.e., tip of the thermocouple sheath) to the measurement junction. Figure 8 shows the temperature signal, as it would be seen at various distances from the surface of the semi-infinite body.

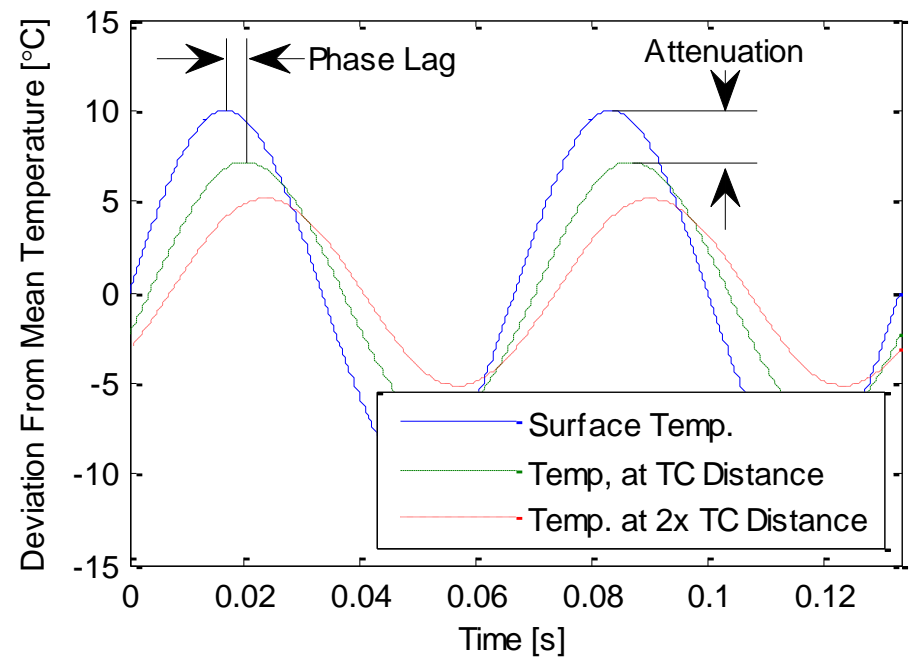

Figure 8: Example of transient temperatures experienced at tool surface and measured at thermocouple (TC) location.

The difficulty in using this formulation for predicting sensor response is in choosing appropriate values for $\alpha$ and $L$. In principle, an average thermal diffusivity could be computed, using a weighted average of material diffusivities tied to their thicknesses, and the distance to the measurement junction, $L$ could be obtained. In practice this is very challenging because the thermal properties are not well 
documented (especially if proprietary materials are used), and it is unknown what tolerance is associated with the distance to the measurement junction. In order to understand the effects of these parameters on sensor response, the average values of $\alpha$ and $L$ were allowed to vary, and design plots were constructed to show the sensor's response (Figure 9). The boxes on these plots represent the assumed range of plausible values for $\alpha$ and $L$ (x and $\mathrm{y}$ axes, respectively). The point indicated by the small circle represents the nominal (to the best available knowledge) values of $\alpha$ and $L$ for the tools being evaluated in this study.

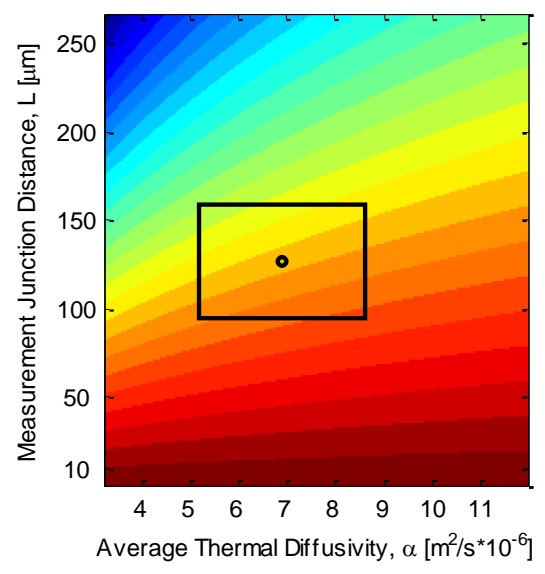

(a)

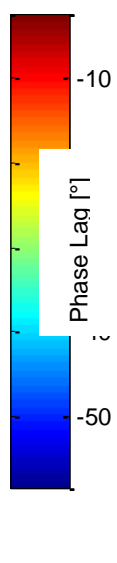

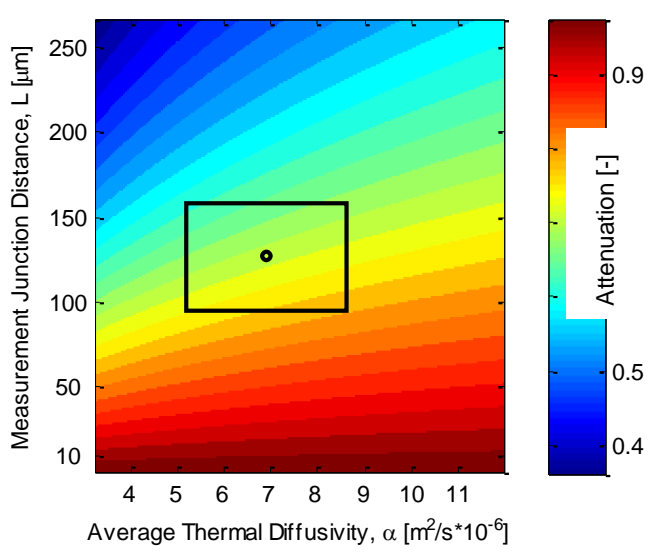

(b)

Figure 9: Sensor design plots based on 1D semi-infinite model for $1000 \mathrm{rpm}$ spindle speed: (a) phase lag of the sensor response (in degrees of tool rotation); (b) attenuation of sensor response.

Figure 9 helps provide some insight into delay and attenuation associated with the measurement. Notice that the delay and attenuation are both more greatly affected by changes in the distance to the measurement junction, $L$, than by the assumed average thermal diffusivity.

\subsection{Development of the Modified Laser Flash Test}

In order to emulate the tool-workpiece interface temperature at a fixed location on the rotating FS tool during a traverse weld (butt or lap) it would be desirable to use a known sinusoidally varying surface temperature as an input and measure the sensor's response. This is difficult to implement as a practical test. Therefore, another method for experimental determination that uses a step change in surface heat flux and/or pulses of heat flux was sought. 
A common test to measure the thermal diffusivity of a substance is outlined in the ASTM E-1461 standard [31]. During this test, a thin disk of material of known thickness is irradiated by a pulse of heat flux (usually applied with a laser) at the front surface while simultaneously measuring the temperature at the rear surface (Figure 10). The time-temperature profile can then be related to the thermal diffusivity of the disk.

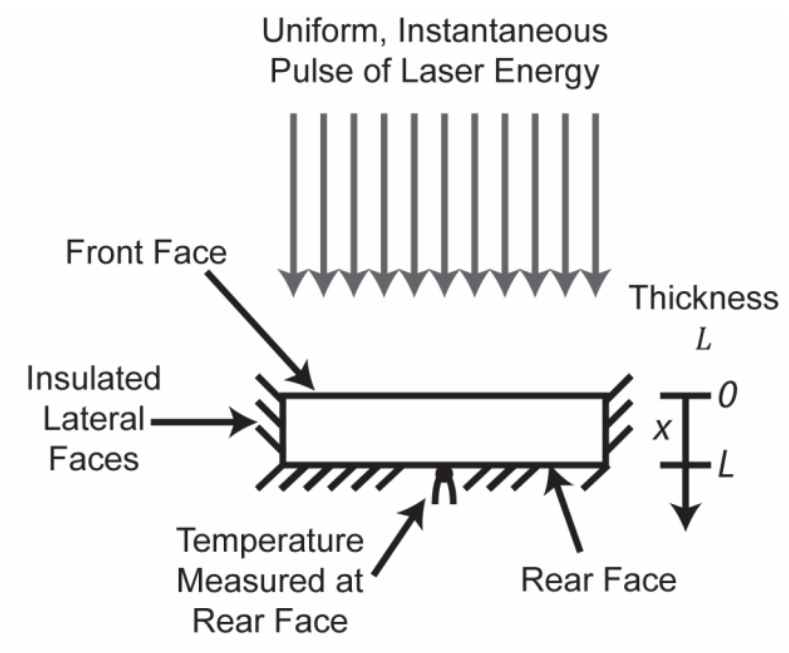

Figure 10: Schematic of the laser flash method [31].

The ASTM E-1461 standard test is not unlike the case of the tool-embedded thermocouple. In the FSW case, the measurement junction is analogous to the temperature at the rear face of the material. The main difference is that in the FSW case, thermal energy continues to diffuse past the measurement junction, whereas in the E-1461 standard, the rear face is assumed to be adiabatic. An approach similar to the E-1461 standard could be used with appropriate modification.

For the ASTM E-1461 test, a thin disk of material is considered with a uniformly distributed energy flux input on the front face, while the sides and back face insulated, i.e., a one-dimensional heat transfer problem. A laser pulse usually delivers the energy. Mathematically this is described as a finite thickness plane, $0<\mathrm{x}<\mathrm{L}$. Laser energy is assumed to be absorbed on the surface at $\mathrm{x}=0$. The timetemperature relationship at the rear face $(\mathrm{x}=\mathrm{L})$ of the disk is given by

$$
T(L, t)=\frac{E^{\prime \prime}}{\rho c L}\left[1+2 \sum_{n=1}^{\infty}(-1)^{n} \cdot \exp \left(\frac{-n^{2} \pi^{2} \alpha t}{L^{2}}\right)\right]
$$


In the ASTM E-1461 standard, this equation is solved for the time taken to reach half the maximum temperature rise, allowing determination of the diffusivity of the material (Eq. 6). Recall that L is known in the ASTM E-1461 test.

$$
\alpha=\frac{0.13879 L^{2}}{t_{1 / 2}}
$$

A similar approach can be applied to a one-dimensional semi-infinite region of material exposed to a pulse of energy at its surface [30].

$$
T(L, t)-T_{i n i}=\frac{E^{\prime \prime}}{\rho c \sqrt{\pi \alpha t}} \exp \left(-\frac{L^{2}}{4 \alpha t}\right)
$$

A curve could be fit to experimental data using this equation to determine the values of $\mathrm{L}$ and $\alpha$. Using this approach it is not possible to solve for $\mathrm{L}$ and $\alpha$ independently. However, it is possible to solve for a new variable, $\tau$, which is defined as

$$
\tau=\frac{L^{2}}{\alpha}
$$

Notice that $\tau$ (Eq. 8) is Eq. (4) squared. The parameter $\tau$ is a diffusive time constant governing the transport of thermal energy into a semi-infinite body. Large values of $\tau$ will lead to slower transport of thermal energy (i.e., slower movement of isotherms); smaller values of $\tau$ will allow interior regions to be affected by boundary conditions more quickly. If $\tau$ can be found, then the thermal dynamic response of the sensor can be predicted.

\section{Experimental Method}

When the instrumented FS tool (Figures 3-4) is used for welding, a wireless data acquisition system [29] is used to transmit temperature and position data from the rotating tool to a stationary computer in real time. For determining the sensor response, the thermocouples were directly connected to a hard-wired, stationary, data acquisition system (Figure 11). The essential feature of this system is simultaneous measurement of the laser pulse and temperature response with the same clock. 


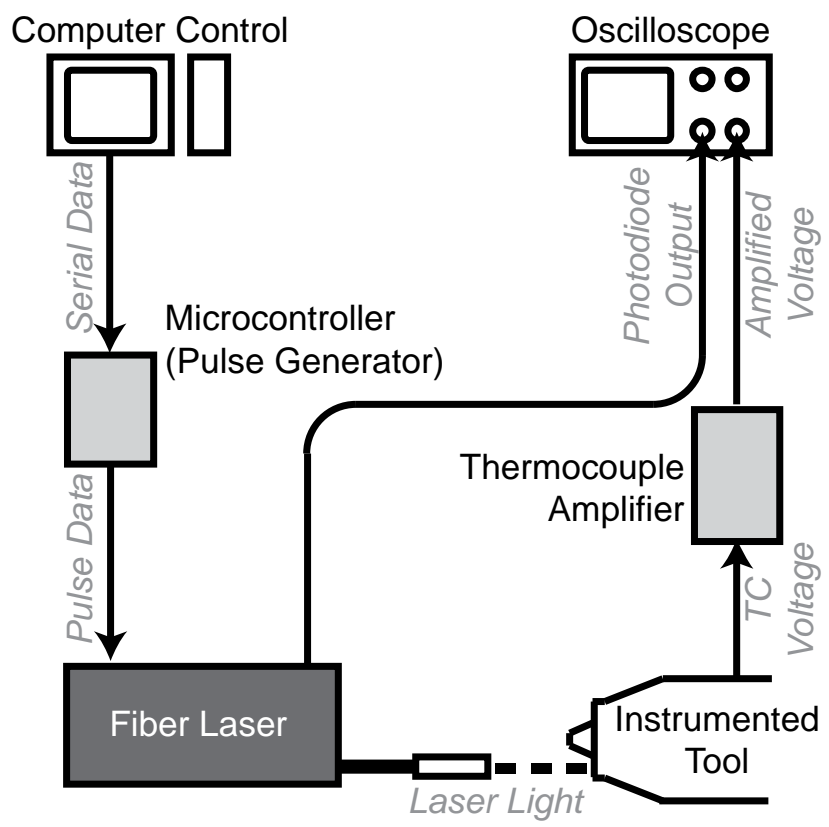

Figure 51: Schematic of data acquisition system for instrumented tool sensor response tests.

The response measurement consists of the instrumented FS tool, a microcontroller used for laser pulse control, an amplifier board, and an oscilloscope (Figure 51). The measurement is initiated by a microcontroller (Arduino UNO) that generates a voltage pulse of a given length upon receiving a pulse command over a serial connection from a computer. The pulse length command was calibrated to achieve an output close to the command value although the exact pulse energy is not crucial to the measurement. This digital level voltage pulse is used as an input to the laser (SPI Lasers redPOWER R4 HS Series) operated in continuous wave mode, at the laser's maximum output power of $200 \mathrm{~W}$. The unfocused beam (5-mm-diameter, Gaussian intensity distribution) is centered on the thermocouple to be tested, ensuring heat flow in only the direction normal to the tool surface (both the probe- and shoulder-embedded thermocouples were tested). Pulse energy is limited by the maximum laser power. While a focused beam would provide higher heat flux values, it may also violate the testing method's assumption of 1-D heat flow because of the Gaussian laser intensity profile. In the mode selected, the laser power is modulated to $100 \%$ of output power at a logic level high voltage on the microcontroller pulse control line. Data on the laser pulse and temperature response was gathered by an oscilloscope (Agilent Model 54622D). An internal photodiode used by the laser for power control was sampled by the oscilloscope and triggered the 
acquisition of data. Upon the beginning of the laser pulse, the output of the photodiode rises, triggering the oscilloscope and collecting data for both the pulse power level and temperature of the thermocouple. A thermocouple amplifier board was connected between the FS tool embedded sensors and the oscilloscope to amplify the signal and perform cold junction compensation.

Tests were conducted with pulse lengths from 100 to 1000 microseconds, in increments of 100 microseconds. Ten replicates were performed at each pulse length tested. For the testing method presented in this work, the pulse energy, which is directly proportional to the pulse length, does not need to be known in order to determine the sensor time constant, $\tau$. The ideal pulse would be significantly shorter than the time constant and deliver sufficient energy to drive the temperature signal above the noise floor of the data.

\section{Results}

Raw data obtained from the oscilloscope consisted of voltage outputs from the photodiode of the laser and the thermocouple amplifier (Figure 12). The noise present in the data made curve fitting unreliable for pulse lengths shorter than 300 microseconds because of the relatively small temperature rise affected by the pulse energy. 

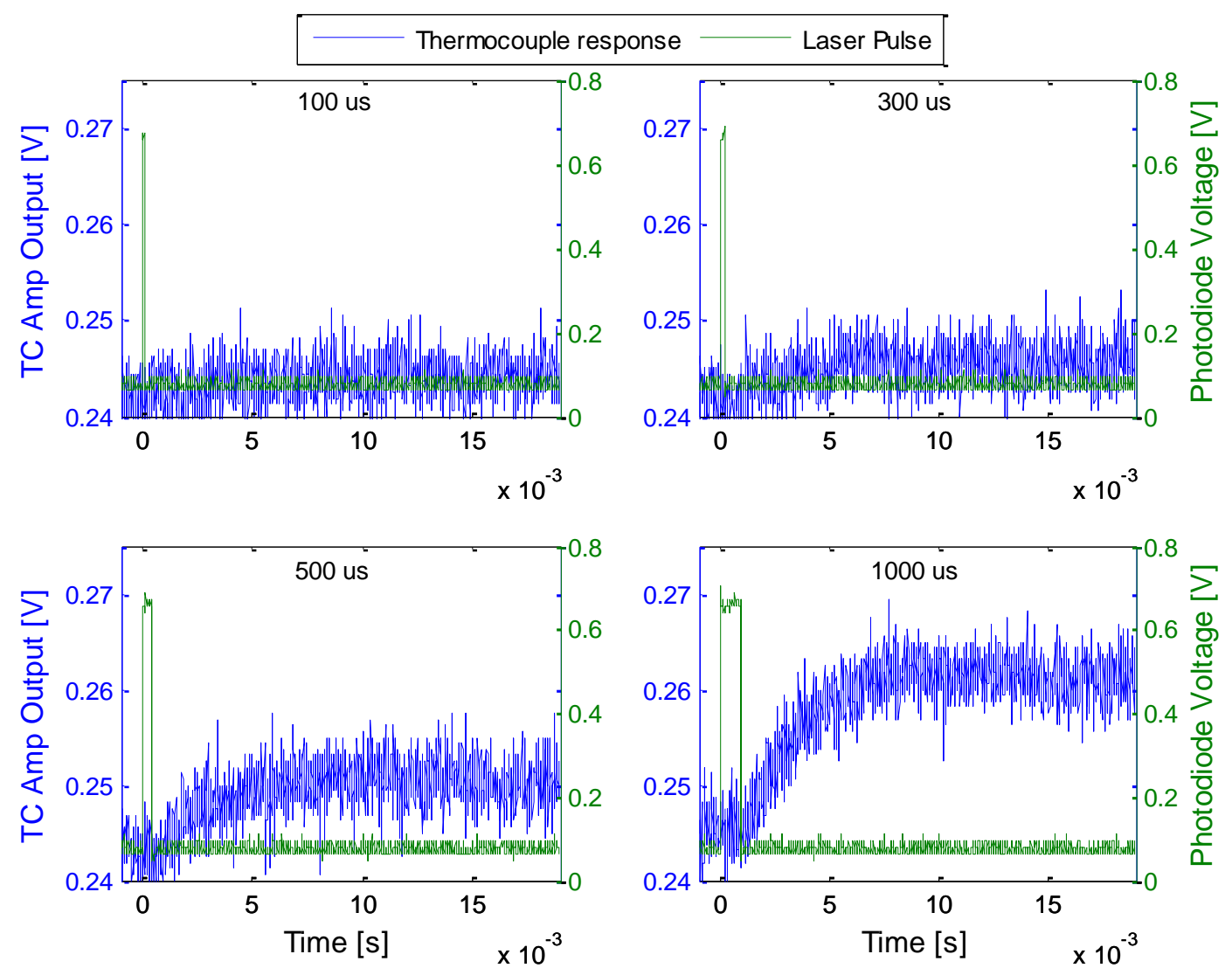

Figure 62: Amplified thermocouple and laser signals collected by oscilloscope.

In order to fit the theoretically derived one-dimensional semi-infinite model, some modifications to Equation (7) were necessary to allow for mathematically correct fitting. Products of constant terms were gathered together to form the following equation

$$
T=T_{0}+\frac{C_{0}}{\sqrt{t}} * e^{-\frac{\tau}{4 t}}
$$

where, $\mathrm{T}_{0}$ and $\mathrm{C}_{0}$ are constants, $\mathrm{t}$ is time, and $\tau$ is the unknown time constant (i.e., regression parameter).

A regression was then performed in MATLAB to fit this model to the experimental data (Figure 13). 


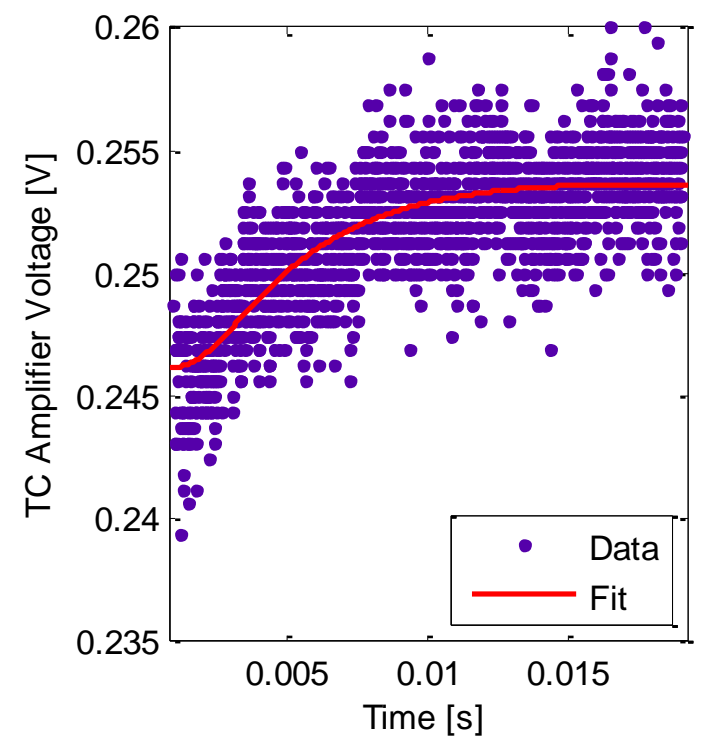

(a)

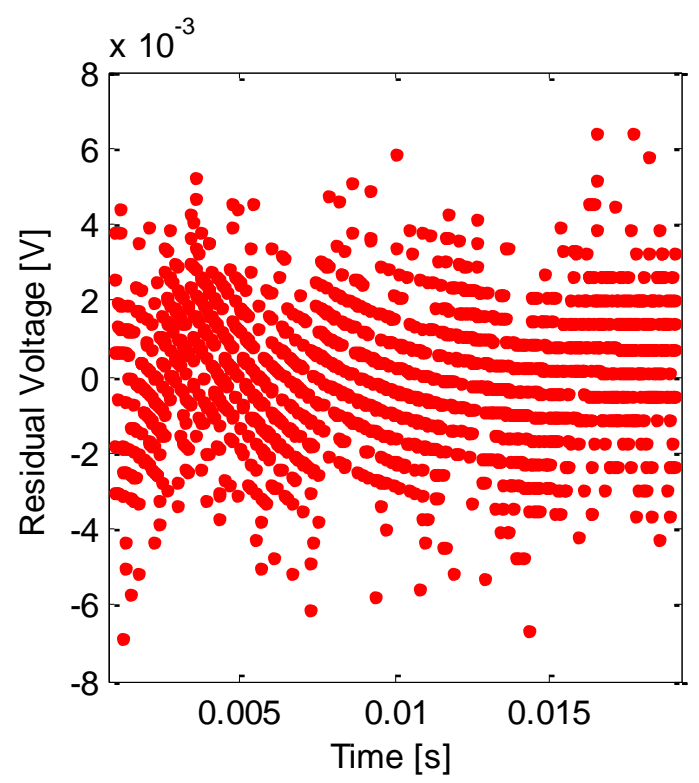

(b)

Figure 73: Data and fit results for a 500us pulse length: (a) data and fit, (b) residuals.

The residuals are uniformly distributed in a band around zero. This indicates that the model describes the data well even if there is a high noise level.

Once the regression parameter (i.e., time constant) has been obtained for each sensor, it can be used to relate the measured temperatures to the true surface temperatures using Equations (2) and (3). Table 1 shows the experimentally measured time constants for four thermocouple sensors embedded in two FS tools: one sensor each in the shoulder and probe (Figure 3). The phase lag (i.e., delay) and attenuation shown in Table 1 are calculated for an FSW tool rotating at a spindle speed of $1000 \mathrm{rev} / \mathrm{min}$.

Table 1: Measured time constant values and their effect on phase lag and attenuation for two instrumented FSW tools rotating at $1000 \mathrm{rpm}$.

\begin{tabular}{lllccc}
\hline & & \multicolumn{2}{c}{ Measured } & \multicolumn{2}{c}{ Calculated for 1000 rpm } \\
\hline Tool & Sensor & $\boldsymbol{\tau}(\mathbf{m s})$ & $\boldsymbol{\sigma}_{\boldsymbol{\tau}}(\mathbf{m s})$ & $\begin{array}{c}\text { Phase Lag } \\
\text { (degrees) }\end{array}$ & $\begin{array}{c}\text { Attenuation } \\
\text { Factor }(-)\end{array}$ \\
\hline L-01 & Probe & 37.1 & 1.26 & 79.9 & 0.248 \\
& Shoulder & 21.5 & 3.30 & 43.0 & 0.472 \\
\hline T-02 & Probe & 42.6 & 0.92 & 85.6 & 0.224 \\
& Shoulder & 22.5 & 1.82 & 43.9 & 0.464 \\
\hline
\end{tabular}

Figure 14 graphically represents the phase lag and attenuation of the measured thermocouple signals in a single rotation of the tool (i.e., 360 degrees) during an FSW weld. The top row of images in 
Figure 14 shows the measured temperatures near the tool-workpiece interface at different angular positions of the FSW tool. The shoulder and probe temperatures have different scales because of the significantly different magnitudes at each location. The bottom row of images in Figure 14 shows the tool-workpiece interface temperatures that have been corrected for attenuation and phase lag based on each individual sensor's time constant (Table 1). In the following plots, the tool is being viewed topdown, with counter-clockwise rotation and travel direction from right to left. Hence, what is referred to in the FSW community as the advancing side of the weld is at the top of the graphs and the retreating side of the weld is at the bottom of the graph. The advancing side corresponds to the highest relative velocity and shear rates in the weld zone.

Measured temperature
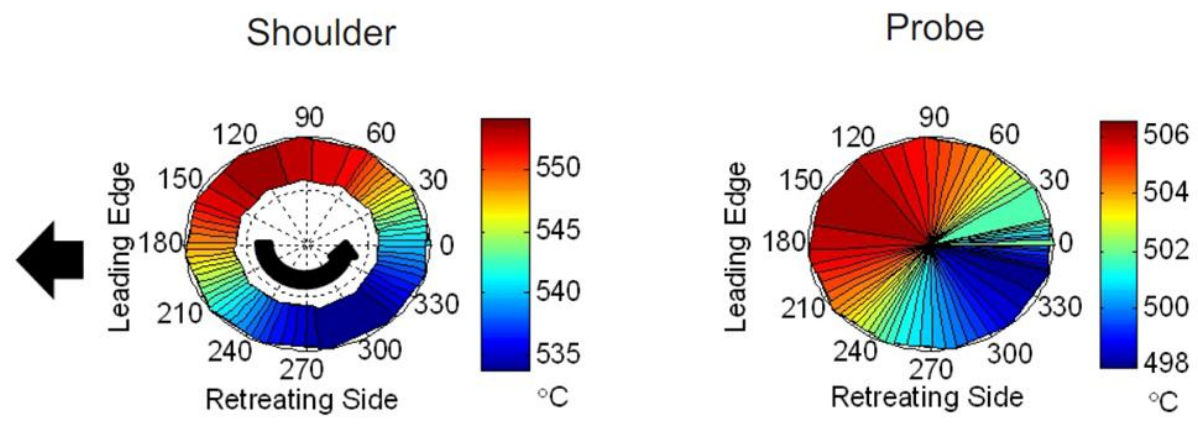

Corrected toolworkpiece interface temperature
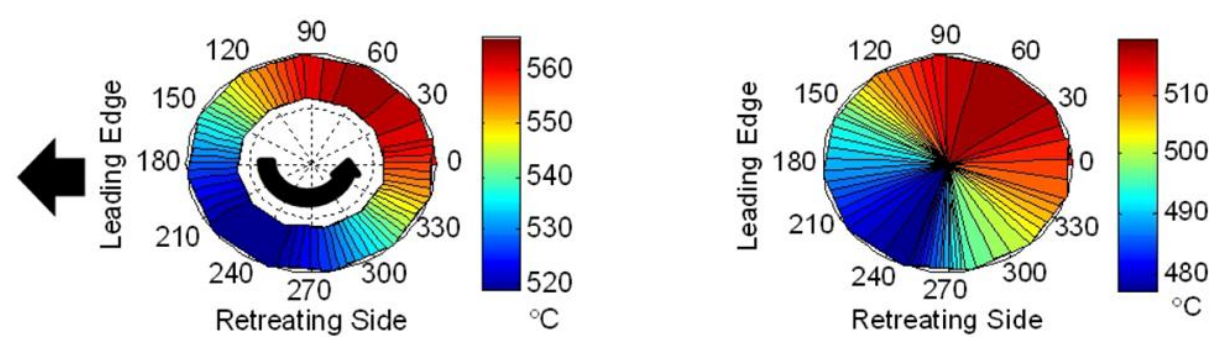

Figure 84: Measured temperature $\left[{ }^{\circ} \mathrm{C}\right]$ and calculated tool-workpiece interface temperature distributions at the shoulder and probe (1300 rpm, $400 \mathrm{~mm} / \mathrm{min}, 6061-\mathrm{T6})$.

It is clear that the temperature corrections have a significant impact on both the location and magnitude of the temperature field despite the fact that the sensors are approximately $100 \mu \mathrm{m}$ from the tool-workpiece interface.

\section{Discussion}


Figure 15 shows the frequency response (phase lag, i.e., delay, and attenuation factor) for the shoulder thermocouple from tool T-01. It is a semi-log plot with rotation frequency and RPM in log scale along the $\mathrm{x}$-axes of the plot. Delay and attenuation factor are calculated by substituting Eq. (8) into Eqs. (3) and (2), respectively. This plot shows how the temperature sensor response is affected by the RPM. It can be noticed that the attenuation factor (plotted along the vertical-right axis) decreases with increase in the spindle RPM. For spindle RPM of 10,000 and above, attenuation factor drops to zero. This suggests that for spindle RPMs of 10,000 and above, the temperature sensor will not capture the dynamic behavior of the temperature. It can also be noticed that the delay (plotted along the vertical-left axis) increases in negative direction with increase in RPM. The delay increases to 6.28 radians $(2 \pi)$ at approximately 3600 RPM. That is, for a spindle speed of 3600 RPM and above, the temperature data will be spatially delayed by at least one complete tool rotation. This will make the accuracy of the temperature data questionable. In other words, a spatial delay of more than 6.28 radians is unacceptable. Therefore, the shoulder temperature sensor on FS tool T-01 can be used to capture data for friction stir welds performed at RPMs less than 3600 . 


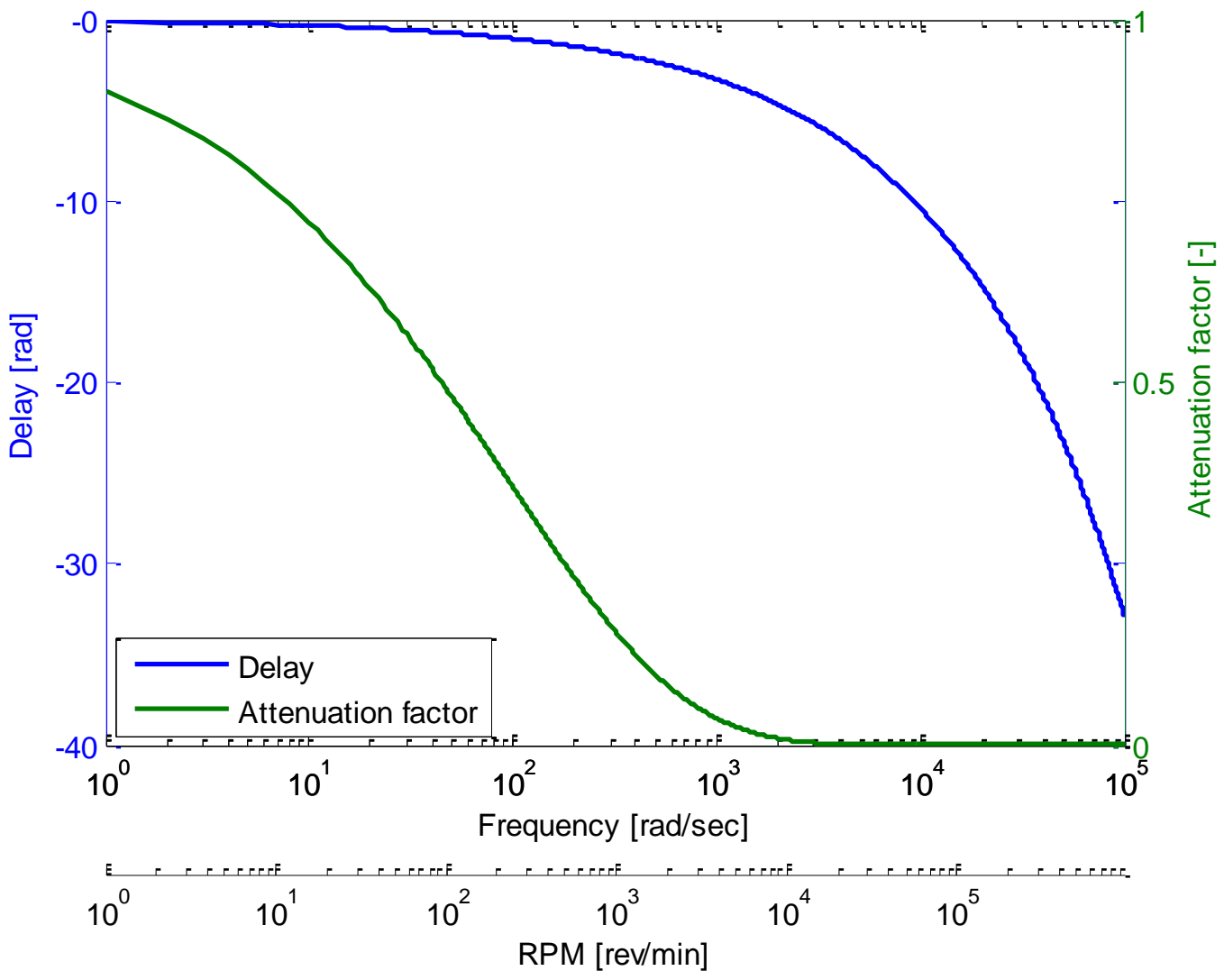

Figure 15. Frequency response for shoulder thermocouple [frequency and RPM are on log scale along x-axes]

In general, the laser flash method for calibration is only useful for temperature sensors that are both small and embedded near the surface of a material. If either of these conditions is not met, the test should not be used. For example, as temperature waves diffuse through the material, they lose amplitude, with the temperature rise being equal to

$$
T_{\max }=\frac{E^{\prime \prime} * e^{1 / 2}}{\rho c L} * \sqrt{\frac{2}{\pi}}
$$

For a sensor embedded 4 millimeters below an $\mathrm{H} 13$ tool steel surface the temperature rise resulting from a laser pulse width of 200 microseconds and absorbed uniform heat flux of $1.02 \times 10^{7}$ $\mathrm{W} / \mathrm{m}^{2}\left(\mathrm{E}^{\prime \prime}=2,040 \mathrm{~J} / \mathrm{m}^{2}\right)$, as used in this study, would be only $0.1^{\circ} \mathrm{C}$. Large sensors would likely also be poor candidates for the test because they allow the possibility of large temperature gradients within them. 
Table 2 compares the predicted and experimentally observed phase lag (i.e., delay) and attenuation for the thermocouple sensors at the FSW tool shoulder and probe used in this study.

Table 2: Comparison of predicted and measured phase lag and attenuation factor for FSW tool rotation rate of $1000 \mathrm{rpm}$.

\begin{tabular}{lccc}
\hline \multicolumn{1}{c}{ Source } & $\boldsymbol{\tau}(\mathbf{m s})$ & $\begin{array}{c}\text { Phase Lag } \\
\text { (degrees) }\end{array}$ & $\begin{array}{c}\text { Attenuation } \\
\text { Factor (-) }\end{array}$ \\
\hline 1-D Semi-Infinite model & & 21 & 0.70 \\
\hline Tool-01 Probe measurement & 37.1 & 80 & 0.25 \\
Tool-01 Shoulder measurement & 21.5 & 43 & 0.47 \\
\hline Tool-02 Probe measurement & 42.6 & 85 & 0.22 \\
Tool-02 Shoulder measurement & 22.5 & 44 & 0.46 \\
\hline
\end{tabular}

The one-dimensional semi-infinite (analytical) predicts a phase lag of 21 degrees and attenuation of $70 \%$. The model does not agree well with the measured values and does not capture the difference between the sensors mounted in the probe and shoulder of the tool. While the shape of the experimental thermocouple response curve does agree well with the curve predicted by the 1-D analytical model, the model has done a poor job at predicting the actual response time of the sensors. There are several reasons for these discrepancies.

The design plots in (Figure 9) show that the sensor position (i.e., distance from the interface) has a larger effect on the dynamic response than the uncertainty in the average material properties. The primary cause of the discrepancy shown in Table 2 is believed to be a result of not knowing the exact position (distance from the surface) of the thermocouple bead after assembly. This variable cannot be independently determined from the time constant, $\tau$. It may be possible to non-destructively measure the thermocouple bead location with a micro-CT system, however, the authors did not have access to such equipment at the time of this study.

Knowing that there is a discrepancy, between the measured and predicted time response, the model can be used to estimate the location of the thermocouple. Because the thermocouple sheath has a diameter of $0.25 \mathrm{~mm}$ it was originally assumed that the thermocouple junction was located $125 \mu \mathrm{m}$ from the tip, i.e., below the surface. The predicted phase lag and attenuation factor for the sensor embedded 
$250 \mu \mathrm{m}$ beneath the tool surface were 43 degrees and 0.37 , respectively. These values are much closer to the ones obtained using the modified laser flash test in Table 2.

There exist several factors that are not likely to cause the magnitude of discrepancy observed. First, there exists a thin layer of aluminum adhered to the surface of the first FS tool tested (T-01). However, aluminum has a relatively high thermal diffusivity and the layer is approximately $100 \mu \mathrm{m}$ thick. A $100 \mu \mathrm{m}$ layer of aluminum would make the response about 150 microseconds slower. Compared to the discrepancy in time constants for the sensors (Table 2), 15 milliseconds, this is negligible. Testing of tool T-02 provides further evidence to this effect: it had never conducted a friction stir weld and thus possessed no adhered aluminum surface layer. Tool T-02 showed response time constants that were within $5.5 \mu$ s of those measured for tool T-01. The second geometric uncertainty that can be discounted as a significant cause of the discrepancy is the sheathed sensor tip not being flush with the tool shoulder surface. There is no visually observable depression at the sensor location and any that does exist would be of similar magnitude as the adhered layer of aluminum that is present after friction stir welding. The third geometric discrepancy between the model and the physical system is the fact that the through hole is not orthogonal to the tool-workpiece interface. From Figure 3 we know that the through hole at the shoulder and probe are 36 degrees and 33 degrees from the surface normal, respectively. These angles will alter the heat flow into the FS tool because of the layers of different materials (hence properties) around the thermocouple bead. However, the overall angle cannot explain the discrepancy between the model and measurements. In addition, the 3 degree difference in angles cannot explain the significant difference in measured response between the probe and shoulder (Table 2).

Another observed result that should be further investigated is the difference in response between the thermocouples embedded at the probe and shoulder. The response of the probe-embedded sensor was slower in both tools tested (Table 1). This suggests that there is a repeatable factor affecting the response at this location, as compared with the shoulder location. Furthermore, the model is not capturing this behavior. Based on distance of the thermocouple from the tool surface alone the longer response time of 
the sensors located in the probe would have to be $328.4 \mu \mathrm{m}$ from the surface as compared to the shoulders' $250 \mu \mathrm{m}$ from the surface. Since all of the sheathed thermocouples come from the same batch this discrepancy would have to come from the placement and cementing of the thermocouple in the through-hole.

\section{Conclusions}

A modification to the ASTM E-1461 laser flash method has been developed as a tool for measuring the dynamic response of thermocouples embedded near the surface of a friction stir weld tool. The one-dimensional transient heat transfer model that is used in ASTM E-1461 is for a thin disk of material that is adiabatic (insulated) on all sides except the surface that is experiencing a heat flux. For this application a one-dimensional transient heat transfer model for a semi-infinite medium is used to represent the temperature sensor that is near the surface experiencing the heat flux with most of the FSW tool's bulk below it. The temperature sensor's time response that is determined with this method can be used to correct for the phase lag and attenuation of the measured signal in order to report the transient temperature at the surface of the FSW tool. The following conclusions can be drawn from this work:

1. This relatively simple method can be used as a practical tool to obtain the dynamic response of the tool-embedded temperature sensor with relative ease. Applications include friction stir welding, transient cutting, etc.

2. The measurement technique is non-destructive, and can be performed in-situ. The time response can be re-measured with metal adhered to the tool surface and at various stages of wear.

3. Many situations similar to that of the tool-embedded temperature sensor are also viable candidates for this test.

4. For the sensors tested, response time constants of 21.5 and 37.1 milliseconds have been measured. For a typical friction stir weld $(1,000 \mathrm{rpm})$, these will result in temperature measurements that lag 
the surface temperature by 43 and 79.9 degrees of tool rotation and are attenuated to $24.8 \%$ and $47.2 \%$ of the actual tool-workpiece interface temperature.

5. The one-dimensional model in combination with the developed experimental method can provide insight into the physical location of the sensor below the surface of the tool. In this study, the predicted time constant was significantly shorter than what was measured with the modified flashdiffusivity method. This indicated that the temperature sensor was actually located further away from the surface than originally thought.

\section{Acknowledgments}

The authors gratefully acknowledge the partial support of this work by the Department of Mechanical Engineering and the College of Engineering at the University of Wisconsin - Madison, the Wisconsin Alumni Research Foundation Technology Development RA, the Machine Tool Technology Research Foundation, and the U.S. National Science Foundation grant CMMI-0824879. The authors would like to thank Professors Nicola J. Ferrier, Neil A. Duffie, and Timothy Shedd, as well as Dr. Edward G. Cole for their valuable discussions and advice.

\section{References}

[1] Thomas W. M., Nicholas E. D., Needham J. C., Murch M. G., Temple-Smith P., and Dawes C.J., 1991, "Friction Stir Butt Welding." International Patent Application No. PCT/GB92/02203 and GB Patent Application No. 9125978.8, U.S. Patent No. 5460317

[2] Shrivastava A., Krones M., and Pfefferkorn F.E., 2015, "Comparison of energy consumption and environmental impact of friction stir welding and gas metal arc welding for aluminum," CIRP Journal of Manufacturing Science and Technology, 9, pp.159-168.

[3] Mishra R. S., and Ma Z. Y., 2005, "Friction stir welding and processing," Materials Science and Engineering: R: Reports, 50(1-2), pp. 1-78.

[4] Threadgill P. L., Leonard A. J., Shercliff H. R., and Withers P. J., 2009, "Friction stir welding of aluminium alloys," International Materials Reviews, 54(2), pp. 49-93.

[5] Peel M., Steuwer A., Preuss M., and Withers P. J., 2003, "Microstructure, mechanical properties and residual stresses as a function of welding speed in aluminium AA5083 friction stir welds," Acta Materialia, 51(16), pp. 4791-4801. 
[6] Gratecap F., Racineux G., and Marya S., 2008, “A Simple Methodology to Define Conical Tool Geometry and Welding Parameters in Friction Stir Welding," 7th International Friction Stir Welding Symposium ,TWI, Published on CD, Awaji Island, Japan.

[8] Edwards P., and Ramulu M., 2010, "Peak temperatures during friction stir welding of Ti-6Al-4V," Science and Technology of Welding and Joining, 15(6), p. 468-72.

[9] Fehrenbacher A., Schmale J., Zinn M. R., and Pfefferkorn F. E., 2012, "Tool-Workpiece Interface Temperature Measurement in Friction Stir Welding," Proceedings of the ASME International Manufacturing Science and Engineering Conference, Notre Dame, IN.

[10] Fehrenbacher A., Duffie N. A., Ferrier N. J., Pfefferkorn F. E., and Zinn M. R., 2014, "Effects of tool-workpiece interface temperature on weld quality and quality improvements through temperature control in friction stir welding," International Journal of Advanced Manufacturing and Technology, 73, pp. 165-179.

[11] Shrivastava A., Dingler C., Zinn M., Pfefferkorn F. E., 2015, " Physics-based interpretation of toolworkpiece interface temperature signals for detection of defect formation during friction stir welding," Manufacturing Letters, 5, pp. 7-11.

[12] Woo W., Feng Z., Wang X. L., Brown D. W., Clausen B., An K., Choo H., Hubbard C. R., and David S. A., 2007, "In situ neutron diffraction measurements of temperature and stresses during friction stir welding of 6061-T6 aluminium alloy," Science and Technology of Welding and Joining, 12(4), pp. 298-303.

[13] Jandric D., Ouyang J. H., Valant M., and Kovacevic R., 2002, "On-line weld quality diagnostics in friction stir welding," Eleventh International Conference on Computer Technology in Welding, 5-6 Dec. 2001, NIST, Boulder, CO, USA, p. 173-81.

[14] Dehelean D., Safta V., Cojocaru R., Halker T., and Ciuca C., 2008, "Monitoring the quality of friction stir welded joints by infrared thermography," Welding in the World, 52(SPEC. ISS.), pp. 621-626.

[15] Covington J. L., Robison W., and Webb B. W., 2005, "Experimental characterization of tool heating during friction stir welding," 7th International Conference on Trends in Welding Research, May 16, 2005 - May 20, 2005, ASM International, Pine Mountain, GA, United states, pp. 179-184.

[17] Chao Y. J., and Qi X., 1998, "Thermal and thermo-mechanical modeling of friction stir welding of aluminum alloy 6061-T6," Journal of Materials Processing and Manufacturing Science, 7(2), pp. 215-233.

[18] Tang W., Guo X., McClure J. C., Murr L. E., and Nunes A., 1998, "Heat input and temperature distribution in friction stir welding," Journal of Materials Processing and Manufacturing Science, 7(2), pp. 163-172.

[19] Gerlich A., Su P., North T. H., and Bendzsak G. J., 2005, "Friction stir spot welding of aluminum and magnesium alloys," Materials Forum, 29, pp. 290-294.

[20] Su P., Gerlich A., Yamamoto M., and North T. H., 2007, "Formation and retention of local melted films in AZ91 friction stir spot welds," Journal of Materials Science, 42(24), pp. 9954-9965.

[21] Fehrenbacher, A., J.R. Schmale, M.R. Zinn, F.E. Pfefferkorn, 2014, "Measurement of ToolWorkpiece Interface Temperature Distribution in Friction Stir Welding," ASME Journal of Manufacturing Science and Engineering, 136(2), DOI: 10.1115/1.4026115.

[22] Sterling C. J., Nelson T. W., Sorensen C. D., Steel R. J., and Packer S. M., 2003, "Friction stir welding of quenched and tempered C-Mn steel," Friction Stir Welding and Processing II, March 2, 2003 - March 6, 2003, Minerals, Metals and Materials Society, San Diego. CA, United states, pp. $165-171$.

[23] Cederqvist L., and Oberg T., 2008, "Reliability study of friction stir welded copper canisters containing Sweden's nuclear waste," Reliability Engineering and System Safety, 93(10), pp. 14911499.

[24] Cederqvist L., Bolmsjo G., and Sorensen C. D., 2008, "Adaptive control of novel welding process to seal canisters containing Sweden's nuclear waste using PID algorithms," FAIM2008, Skovde, Sweden. 
[25] Cederqvist L., Johansson R., Robeitsson A., and Bolmsjo G., 2009, "Faster temperature response and repeatable power input to aid automatic control of friction stir welded copper canisters," Friction Stir Welding and Processing V, 15-19 Feb. 2009, Metals \& Materials Society (TMS), Warrendale, PA, USA, pp. 39-43.

[26] Cederqvist L., Reynolds A. P., Sorensen C. D., and Garpinger O., 2010, "Reliable FSW of Copper Canister Using Improved Process and Regulator Controlling Power Input and Tool Temperature."

[27] Blignault C., Hattingh D. G., Kruger G. H., van Niekerk T. I., and James M. N., 2008, "Friction stir weld process evaluation by multi-axial transducer," Measurement: Journal of the International Measurement Confederation, 41(1), pp. 32-43.

[28] Hattingh D. G., Blignault C., van Niekerk T. I., and James M. N., 2008, "Characterization of the influences of FSW tool geometry on welding forces and weld tensile strength using an instrumented tool," Journal of Materials Processing Technology, 203(1-3), pp. 46-57.

[29] Fehrenbacher A., Duffie N. A., Ferrier N. J., Pfefferkorn F. E., and Zinn M. R., 2011, "Toward Automation of Friction Stir Welding Through Temperature Measurement and Closed-Loop Control," Journal of Manufacturing Science and Engineering, 133(5), p. 051008.

[30] Nellis G., 2009, Heat Transfer, Cambridge University Press, Cambridge ; New York.

[31] ASTM E1461 - Standard Test Method for Determination of Thermal Diffusivity by the Flash Method, ASTM International, West Conshohocken, PA.

[33] Nellis, G. and Klein, S., 2009, Heat Transfer, Cambridge University Press, New York. 